\title{
Eskola-doikuntza: kontzeptua, adierazleak, ereduak, neurketa, aldakortasuna eta hari lotutako aldagaiak
}

Oihane Fernández-Lasarte

Didaktika eta Eskola Antolakuntza Hezkuntza eta Kirol Fakultatea (UPV/EHU)

oihane.fernandezl@ehu.eus

Eider Goñi Palacios

Bilakaeraren eta Hezkuntzaren Psikologia Hezkuntza eta Kirol Fakultatea (UPV/EHU) eider.goni@ehu.eus

Igor Camino Ortiz de Barrón

Hezkuntzaren Teoria eta Historia Hezkuntza eta Kirol Fakultatea (UPV/EHU) igor.camino@ehu.eus

Iratxe Antonio-Agirre

Bilakaeraren eta Hezkuntzaren Psikologia Hezkuntza eta Kirol Fakultatea (UPV/EHU) iratxe.antonio@ehu.eus

DOI: http://dx.doi.org/10.1387/tantak.19830

GAKO-HITZAK: eskola-doikuntza; errendimendu akademikoa; eskolaintegrazioa; itxaropen akademikoak; nerabezaroa; berrikusketa.

\section{SARRERA}

Azken hamarkadetan nerabeen eskola-doikuntzari buruz egin diren ikerketetan, garatzen ari diren gazteen gabeziak lehenetsi dira batik bat, eta alde batera utzi dira haien gaitasunak eta ahalmenak. Gabezietan oinarritutako ikuspuntutik aztertu dira, hain zuzen ere, ikaskuntza-arazoak, ezgaitasunak, arreta-gabezia nahasmenduak eta hiperaktibitatea, jokaera antisozialak, droga-abusua, motibazio baxua eta lorpen maila baxua (Damon, 2004). Hala ere, gaur egun garapen positiboa kontuan hartzeko beharrari 
eutsi zaio, hainbat testuingurutan hazteko eta gaitasun soziala areagotzeko prozesu bezala, eremu sozialean eta akademikoan arrakasta izateko aldera. Psikologia positiboaren eremu teorikoa oinarri hartuz(Seligman eta Csikszentmihaly, 2000), garapen positiboaren ikuspegiak ez du nerabezaroa hausturen eta arazoen etapatzat bezala identifikatzen; aldiz, ikaskuntzaren eta aukeren aldi ebolutibotzat jotzen du (Oliva et al., 2010). Nerabezaroan, sozialki heldu osasuntsuak eta trebeak izatea lortzeko bultzatu behar diren aktibo ugarien artean (Lippman et al., 2014) aipagarrienetako bat da eskola-doikuntza, gizartean egokitzeko adierazle garrantzitsua izaki.

Ikerlan honetan, berrikusketa teoriko bat egingo da eskola-doikuntzaren inguruko kontzeptualizazioari, adierazleei eta hura azaltzen duten ereduei buruz. Horrez gainera, eskola-doikuntzari lotutako testuinguru-aldagaiak aztertuko dira.

\section{ESKOLA-DOIKUNTZAREN KONTZEPTUA}

Bronfenbrenner-en (1979) ikuspegi ekologikoaren arabera, gazteen garapen kognitibo, sozial eta afektiboa gazteak dauden testuinguruetan gertatzen da: eskolan, familiartean eta komunitatean. Beraz, eskolaren testuinguruan doikuntza funtsezkoa da ikasleak erabat garatu ahal izateko.

Eskola-doikuntzari buruz gehien onartu den definizioetako batek eskolako testuinguruko lanei edo beharrei aurre egiteko ikasleek behar dituzten gaitasunak ditu oinarritzat, edo, bestela esanda, eskolako testuinguruetako behar kognitibo eta pertsona artekoetara egokitzeko gaitasuna (Ladd, 1989). Ladd-en (1989) eskola-doikuntzaren eredua Brofenbrenner-en (1979) ikuspegian oinarritzen da, eta prozesu konplexutzat hartzen du eskola-egokitzapena, faktore askoren mende dagoena: eskola, familia eta komunitatea. Zehatz-mehatz, honako hauen arteko loturaren emaitza gisa azal daiteke eskola-doikuntza: ezaugarri pertsonalak - generoa eta adimena-, trebetasun akademiko eta sozialak, laguntzak eta estres-eragileak - eskolan, familian eta komunitatean - , eta eskola-beharrak (1. irudia).

Eskolako giroari dagokionez, garrantzitsua da kontuan hartzea aurrez izan den eskola-esperientzia, eskolan izandako parte-hartzea, itxaropenak eta irakasleen eskutik jasotako laguntza, ikaskideekiko izandako onarpenedo baztertze-harremanak; familiaren testuinguruan, berriz, eragina dute familia-bizitzan jazotakoek eta gurasoen parte-hartzeak eskolan; komunitatean, garrantzitsuak dira lagunak eta harreman-sarea. Aipatutako guztiak dira prestatzen eta laguntzen duten esperientziak. Azkenik, eskolako beharren ildoan, hezkuntza-etapa desberdinetan sartu eta aurrera egin ahal izateak kide- eta irakasle-talde berriek onartu behar izatea dakar, eskolako testuinguruan egokitzea lortzea eta lanetan arrakasta lortzeko trebetasunak garatzea. Ikasleen jokabide-eredua ikasgelako kideekin eta irakasleekin dituzten harremanen mende dago; jokabide eta harreman horiek eragina dute eskola-doikuntzan (Ladd, Kochenderfer-Ladd, eta Rydell, 2011). 


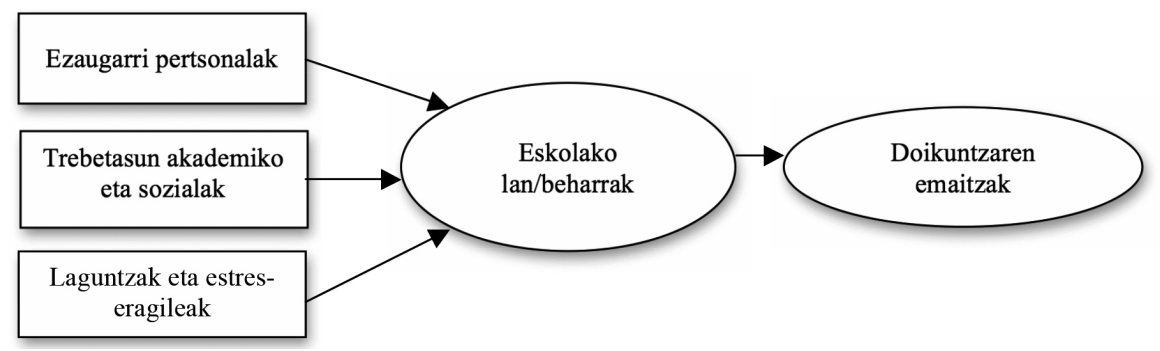

1. irudia

Ladd-en (1989) eskola-doikuntzaren eredua

Gaur egun, doikuntzaren kontzeptuak egokitzapenarekin lotuta egoten jarraitzen du, baita gaitasun sozialarekin ere, pertsona garatuz doan heinean jokaera egokiak hautatzea ahalbidetzen baitu aurki daitezkeen zereginen aurrean (Rodríguez-Fernández, Ramos-Díaz, Madariaga, Arrivillaga, eta Galende, 2016). Gauzak horrela, hezkuntza-sistemaren eskakizun eta ezaugarrietara sozialki zenbateraino egokitzen den erakusten duen adierazlea da eskola-doikuntza, hots, ikasleek eskolan duten gogobetetasun-, integrazio- eta konpromiso-maila neurtzeko (Azpiazu, Esnaola, eta Ros, 2014).

\section{ESKOLA-DOIKUNTZAREN ADIERAZLEAK ETA EREDUAK}

Errendimendu akademikoak, hezkuntza-itxaropen handiek eta kide eta irakasleekiko jokaera egokiak erakusten dute ikasleak nola egokitzen diren eskola-sistemara (Rodríguez-Fernández, Droguett, eta Revuelta, 2012). Hainbat egilek ikertu dute ikasle nerabeek hezkuntzan dituzten itxaropenek zer-nolako lotura duten eskola-doikuntzarekin (Kiuru, Aunola, Vuori, eta Nurmi, 2007). Gerora izango duten ibilbide akademikoarekin lotutako itxaropenak, hau da, prestakuntza akademikoarekin jarraitzeko edo ez jarraitzeko itxaropenak, antzekoak dira talde bereko kideen artean, eta eskola-doikuntzarekin daude lotuta. Zehatzago azaltzeko, hezkuntza-itxaropenek lorpen akademikoekin eta jokaera egokitu gabeekin dute zerikusia, alegia, zenbat eta hezkuntza-itxaropen handiagoa izan, orduan eta lorpen akademiko gehiago eta arazoak sortzen dituzten jokabide gutxiago izango dira. Aldiz, zenbat eta hezkuntza-itxaropen gutxiago izan, arazoak sorrarazten dituzten are jokaera gehiago eta errendimendu akademiko baxuagoa izango da.

Era berean, eskola-doikuntza ebaluatzeko hiru adierazle daude: lorpen akademikoa, eskolarekiko gogobetetasuna eta eskolako inplikazioa. Eskolara behar bezala egokitzen diren ikasleek irakaskuntza balioesten dute, konprometitzen dira, irakasleen eta kideen artean harreman onak izan ohi dituzte eta ez dute jokaera disruptiborik izaten (Kiuru, Nurmi, Aunola, eta Salmela-Aro, 2009). 
Eskola-doikuntza hiru faktore hauek ere definitzen dute: eskola-errendimendu onak, ikasketekin jarraitzeko eta horiek amaitzeko itxaropen handiek eta eskolan integratzeko arazo ezak (Moral de la Rubia, SánchezSosa, eta Villarreal-González, 2010).

Azkenik, errendimendu edo gaitasun akademikoaz gainera, aipatzen da integrazio soziala eskolan, irakasle-ikasleen arteko harremanen kalitatea eta familiaren inplikazioa ere garrantzitsuak direla (Cava, Povedano, Buelga, eta Musitu, 2015).

Oro har, 1. taulan ikus daitekeen moduan, kontuan hartu diren dimentsioak, interakzioak eta ikasleengan eragina dutenak, hainbat ikerketatan errepikatzen dira.

1. taula

Eskola-doikuntzaren adierazleak

\begin{tabular}{|l|l|}
\hline \multicolumn{1}{|c|}{ Egileak eta urtea } & \multicolumn{1}{|c|}{ Eskola-doikuntzaren adierazleak } \\
\hline $\begin{array}{l}\text { Estévez, Murgui, Ruiz, Moreno eta } \\
\text { Musitu (2007) }\end{array}$ & $\begin{array}{l}\text { Eskola-porrota Integrazio arazoak } \\
\text { Itxaropen negatiboak Indarkeriazko jokaera } \\
\text { Pertsonarteko arazoak Biktimizazioa }\end{array}$ \\
\hline Kiuru, Aunola, Vuori eta Nurmi (2007) & $\begin{array}{l}\text { Ikasleen hezkuntza-itxaropenak } \\
\text { Lorpen edo errendimendu akademikoa } \\
\text { Jokaera egokitu gabeak }\end{array}$ \\
\hline $\begin{array}{l}\text { Kiuru, Aunola, Nurmi, Leskinen eta } \\
\text { Salmela-Aro (2008) }\end{array}$ & Burnout-a eskolan \\
\hline $\begin{array}{l}\text { Kiuru, Nurmi, Aunola eta } \\
\text { Salmela-Aro (2009) }\end{array}$ & $\begin{array}{l}\text { Lorpen akademikoa } \\
\text { Eskolarekiko gogobetetasuna } \\
\text { Inplikazioa eskolan }\end{array}$ \\
\hline $\begin{array}{l}\text { Moral de la Rubia, Sánchez-Sosa eta } \\
\text { Villarreal-González (2010) }\end{array}$ & $\begin{array}{l}\text { Errendimendua eskolan } \\
\text { Itxaropen akademikoak } \\
\text { Integrazioa eskolan }\end{array}$ \\
\hline $\begin{array}{l}\text { Rodríguez-Fernández, Droguett eta } \\
\text { Revuelta (2012) }\end{array}$ & $\begin{array}{l}\text { Errendimendua eskolan } \\
\text { Itxaropen akademikoak } \\
\text { Integrazioa eskolan }\end{array}$ \\
\hline $\begin{array}{l}\text { Cava, Povedano, Buelga eta Musitu } \\
\text { (2015) }\end{array}$ & $\begin{array}{l}\text { Errendimendu eta gaitasun akademikoa } \\
\text { Integrazioa eskolan } \\
\text { Ikasleen eta irakasleen arteko harremanak } \\
\text { Familiaren inplikazioa }\end{array}$ \\
\hline
\end{tabular}


Literatura zientifikoan konstruktuaren kontzeptualizazioaren inguruan adostasunik aurkitu ez bada ere, gaur egun, eskola-doikuntzaren egitura dimentsio-anitza dela egiaztatu da. Ikertzaile batzuek faktore kognitiboei, jarrerazkoei eta jokaerazkoei ematen diete garrantzia eskola-doikuntzan (Harrison, Clarke, eta Ungerer, 2007). Halaber, proposatu da eskola-doikuntza zenbaterainokoa den jakiteko errendimendu akademikoa, eskolako egokitzapena, eskolako inplikazioa eta jarrerak hartu behar direla kontuan (Madariaga, Arribillaga, eta Zulaika, 2014). Era berean, eskola-doikuntzaren lau dimentsio proposatzen dira - akademikoa , soziala, eskolakoa eta jokaerazkoa - eta horien adierazle moduan honako hauek: errendimendu akademikoa, kideekiko eta kide-irakasleen arteko elkarrekintza soziala, ikasketekiko jarrera, eskolako inplikazioa eta indarkeriazko jokaerek eta jokaera disruptiboek dakartzaten arazoak (Martínez-Ferrer, 2009).

Jarraian, aztertutako proposamen gehienetan ageri diren eskola-doikuntzaren adierazleak azalduko dira teorikoki: eskola-errendimendua, itxaropen akademikoak eta eskolako integrazioa.

\subsection{Errendimendua eskolan}

Eskola-errendimendua esaten zaio diziplina baten inguruko ezagutzari, adina eta eskolako batezbestekoa erreferentziatzat jota (Torres eta Rodríguez, 2006). Errendimendu aproposa izatea ikaskuntza onarekin dago lotuta, eta irakasgaietan lortutako kalifikazioen bidez adierazten da. Halaber, errendimendu altua duten ikasleak hobeto egokitu ohi dira eskolan: autoritatea onartzen dute, kideekin eta irakasleekin arazo gutxiago dauzkate eta erantzukizun handiagoa hartzen dute (Rosário et al., 2012).

Literatura zientifikoaren arabera, errendimendu akademikoan eragina duten aldagaiak faktore pertsonal, sozial eta testuingurukoetan sailkatu daitezke (Lee eta Shute, 2010; Suárez-Álvarez, Fernández-Alonso, eta Muñiz, 2014). Hain zuzen ere, hona hemen eskolako errendimenduan esku hartzen duten zenbait faktore: ikasleak eta haien ezagutza, irakasleak eta ikasketen programazioa, familia eta seme-alaben eskola-jardueraren segimendua, administrazioa eta hezkuntza-sistemaren kalitatea eta gizartean zentroek duten eraginkortasunaren balorazioa (Adell, 2006). Alabaina, irakasleen irakaskuntza konstruktibistan, ikasleen errendimendu akademiko handiagoarekin lotzen dena, eragina dute ikasgelan ikasle-kopuru txikiagoa izateak, irakasleen esperientziak, prestakuntza jarraituak eta ikasleekiko harreman pertsonalak (Rosário, Núñez, Valle, Paiva, eta Polydoro, 2013). Ildo horretan, nabaria da errendimendu akademikoaren eta ikasleei dagozkien hainbat aldagairen arteko lotura (Núñez, Vallejo, Rosário, Tuero, eta Valle, 2014): aurretiazko ezagutzak, eskolara joatea, ikasketa-maila, gurasoek dituzten itxaropenak eta, batik bat, irakasleen irakaskuntza-ikuspegia. 
Laburbilduz, errendimendu akademikoa konstruktu konplexu bezala definitzen da, elkarrekin erlazionatzen diren faktore ugarik zehazten dutena.

\section{Eskola-errendimendua azaltzeko ereduak}

\section{A) AUTOKONTZEPTUA, MOTIBAZIOA, ITXAROPENAK ETA MAILA SOZIOEKONOMIKOA ERRENDIMENDU AKADEMIKOA AURREIKUSTEKO}

Nerabeez osaturiko lagin batean, enpirikoki frogatu da errendimendu akademikoak lotura duela autokontzeptu akademikoarekin, adierazle sozioekonomiko eta kulturalarekin (faktore bitartekaria), itxaropen akademikoekin eta motibazioarekin (Suárez-Álvarez et al., 2014). Aldagai horiek guztiek errendimendua \%70era arte azaltzen dute (2. irudia).

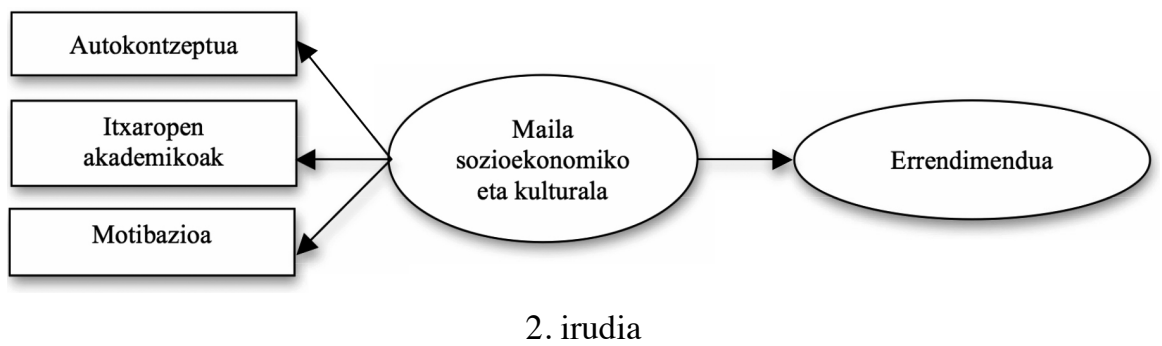

Egitura-ekuazioen eredua errendimendu akademikoa aurreikusteko

\section{B) Pertsonalitatearen ETA ERRENDIMENDU AKADEMIKOAREN FAKTORE BIKO EREDUA}

Eredu hau pertsonalitatearen eredua ebaluatzean datza, errendimendu akademikoa aurreikusteko (McAbee, Oswald, eta Connelly, 2014). Errendimendua definitzean, kalifikazioez beste, kontuan hartzen dira jokabide intelektualak, pertsonartekoak eta intrapertsonalak ere. Hain zuzen ere, hiru eremutan sailkatzen diren hamabi dimentsio ezartzen dira. Jokabide intelektualak esaten zaie ezagutzari eta ongi jakiteari, ikaskuntza jarraituari eta balorazio artistiko eta kulturalari. Pertsonarteko jokabidetzat hartzen dira aniztasunaren balorazioa, lidergoa, komunikazioa eta gizarte eta herritar erantzukizuna. Azkenik, jokabide intrapertsonalen artean daude osasun fisiko eta psikologikoa, ikasketen orientazioa, egokitzapena, pertseberantzia, etika eta integritatea. 


\section{C) ERRENDIMENDU AKADEMIKOAREN EREDU KOGNITIBO SOZIALA}

Norberaren eraginkortasuna da ikasleen errendimendu akademikoan gehien eragiten duen konstruktu nagusietako bat (Valle et al., 2015). Hainbat ikerketaren arabera, norberaren eraginkortasunak errendimendua aurreikusten du (Zuffianò et al., 2013). Beste batzuek (Zalazar-Jaime, Cupani, eta De Mier, 2015), aldiz, Bandura-k (1997) proposatutako norberaren eraginkortasunaren lau iturrietako egitura faktoriala ebaluatzen dute - maisutza-esperientzia, pertsuasio sozialak, egoera fisiologiko eta emozionalak eta ikaskuntza bikarioa - errendimenduan eragin baitezake. Errendimendu akademikoaren eredu kognitibo sozialak aipatutako elementu guztiak barnean hartzen ditu (Lent, Brown, eta Hackett, 1994) eta errendimendu akademikoa azaltzeko oinarria dauka pertsonaren (norberaren eraginkortasuna), giroaren (laguntza soziala) eta jokabidearen (helburuak) arteko interakzioa. Norberaren eraginkortasuna esaten zaio ekintzak behar bezala burutzeko gaitasunean sinesteari; emaitzen itxaropenei, jokabideen ondorioei buruzko iritziari; helburuei, jardueretako parte-hartzeari; eta interesei, motibazioari (3. irudia).

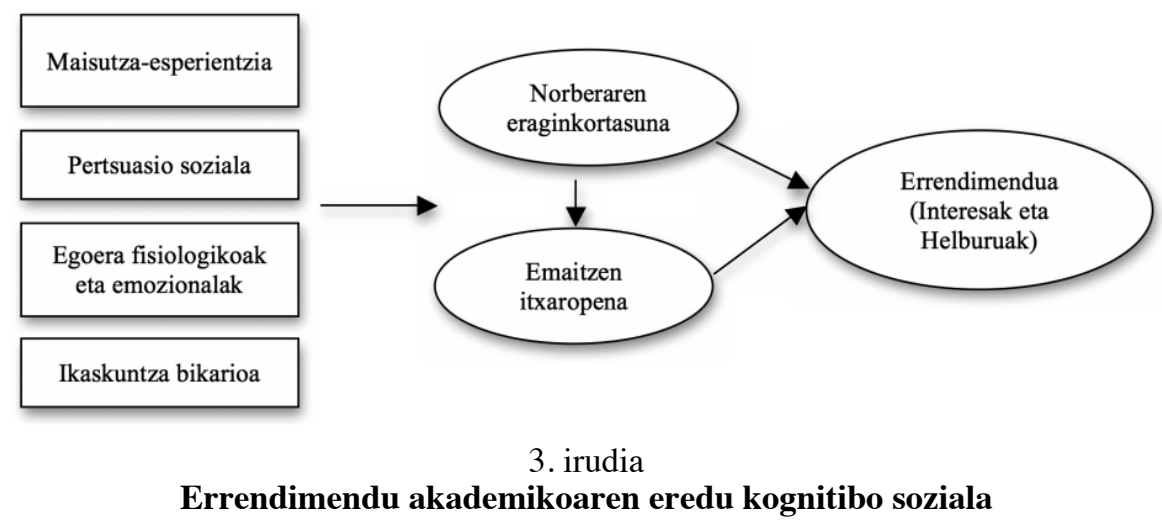

\subsection{Itxaropen akademikoak}

Bandura-ren (2001) teoria sozial-kognitiboaren arabera, norberaren itxaropen akademikoak ikasleek nahi dituzten emaitzak lortzeko euren eraginkortasunaren inguruan dituzten sinesteak dira. Emaitzen itxaropen horiek lorpena aurreikusten dute, eragina dutelako pentsamendu optimistan eta motibazioa direlako oztopoen aurrean ekiterakoan.

Hezkuntza-sisteman helburuak lanez eta ahaleginez lortzeko ikasleak dituen asmoak bezala ere definitzen dira itxaropen akademikoak (Kiefer 
eta Ryan, 2008). Beraz, itxaropenek etorkizun akademikoari egiten diote erreferentzia; hots, ikasketekin jarraitzeko asmoa erakusten dute. Horregatik guztiagatik, eskola-ibilbidean dauden itxaropenek erantzukizunak hartzea dakar, eta eskola-egokitzapenarekin lotuta egoteaz gain, arrakasta akademikoa aurreikusten du horrek (Suárez-Álvarez et al., 2014). Itxaropenak oso garrantzitsuak dira etorkizuneko ibilbidea sustatzen dutelako eta itxaropen horietan kide, irakasle eta gurasoek eragina dutelako (Nurmi, 2004). Alde batetik, gurasoen itxaropenek seme-alaben barne-motibazioan eragin positibo handiagoa dute seme-alabek berek dituzten itxaropenek baino, eta lorpena aurreikusten dute epe luzera (Froiland eta Davison, 2016). Bestetik, irakasleek ikasleen itxaropenetan ere badute eragina, norberak betetako profezia (Hargreaves, 1978) izan daiteke eta era berean eragin ikasleen autokontzeptuan, errendimenduan eta lorpenean.

\section{Itxaropen akademikoak azaltzeko ereduak}

\section{A) ItXARopen-BALIOAREN EREdUA (ECCLES ETA Wigfield, 2002)}

Motibazio-teoria bat da, itxaropenean oinarritzen dena eta Bandura-ren $(1997,2001)$ itxaropenetan oinarritzen dira. Ereduaren arabera, lanen balioak eta itxaropenek zuzenean eragiten dute errendimenduan, iraunkortasunean eta jardueraren hautaketan. Aldagai kognitibo eta sozialak dira, pertsonak berak besteengandik eragina jasotzen duelako, era berean. Hau da, faktore psikologiko, sozial eta kulturaletara daude lotuta itxaropenak eta balioak, eta eskola-doikuntzan laguntzen dute.

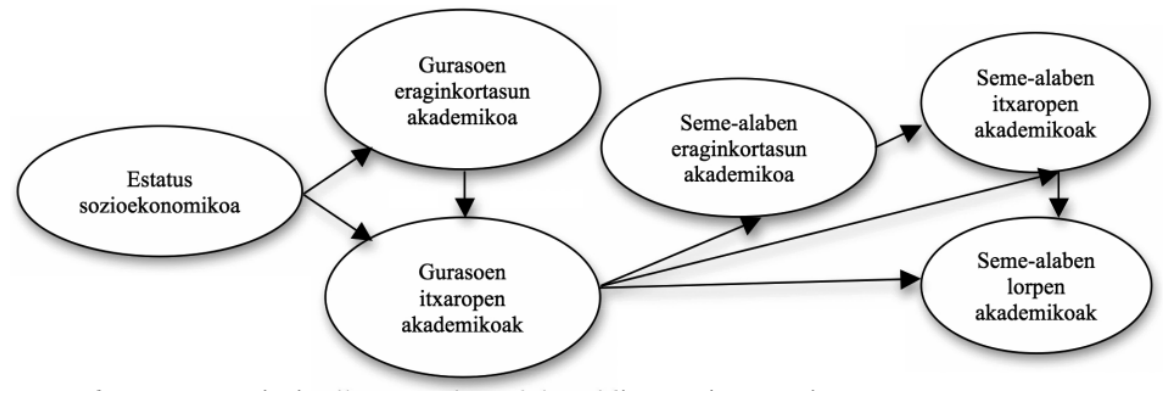

4. irudia

Itxaropen akademikoen eragin soziokognitiboen egitura-eredua 
B) ITXAROPEN AKADEMIKOETAKO ERAGIN SOZIOKOGNITIBOEN EGITURA-EREDUA (BANDURA, BARBARANELli, CAPRARA, ETA PASTORELli, 2001)

Egitura-eredu honek dio familiaren maila sozioekonomikoak eragina duela hautematen den eraginkortasunean eta gurasoek dituzten itxaropen akademikoetan; era berean, zerikusia du seme-alaben eraginkortasunarekin, itxaropen akademikoekin eta eskola-lorpenekin (4. irudia). Hots, familiak zenbat eta maila sozioekonomiko altuagoa izan, orduan eta handiagoak izango dira gurasoen hezkuntza-itxaropenak, eta horiek seme-alaben itxaropen akademikoekin eta eskola-lorpenekin lotzen dira.

\subsection{Integrazioa eskolan}

Eskolako ingurunera egokitzeari esaten zaio eskola-integrazioa (Rodríguez-Fernández et al., 2012). Ildo horretan, eskolara behar bezala egokitzeko kontuan hartu behar da, errendimenduaz gainera, eskolan eta ikasgelan dagoen integrazio sozial maila; horretarako, ikasleen arteko eta irakasleekiko harremanen kalitatea aztertu behar da. Eskola-doikuntza eskasak egokitzeko zailtasunekin du zerikusia, baita bestelako faktoreekin ere, hala nola, ikaskide eta irakasleekiko arazoekin, indarkeriazko jokabideekin, jokabide disruptiboekin, eskolara ez agertzearekin eta eskola uztearekin (Cava, Povedano, Buelga, eta Musitu, 2015). Labur esanda, integrazioa ezinbestekoa da hezkuntzaren testuinguruan; eta kideekin zein irakasleekin izan litezkeen arazoek planteatutako helburuak lortzea zaildu dezakete (Álvarez-García, Núñez, Rodríguez, Álvarez, eta Dobarro, 2011).

\section{ESKOLA-DOIKUNTZAREN NEURKETA}

Eskola-doikuntza zuzenean neurtzen duten tresnak daude, dimentsioak edo osagai batzuk oinarri dituztenak:

- Autoritate Instituzionalarekiko Jarrera Eskala (Reicher eta Emler, 1985). Eskolarekiko eta irakasleekiko jarrera neurtzeko 10 item ditu. Tresna honetan 2 eremu - eskola eta legea - eta 4 faktore hartzen dira kontuan: sistemarekiko loturarik eza, arauei buruzko ideia, autoritateari buruzkoa eta eskolako harremanak.

- Doikuntza Unibertsitatean neurtzeko Eskalak (SACQ) (Baker eta Siryk, 1984, 1989) 67 item ditu eta 4 dimentsio: doikuntza akademikoa, soziala, pertsonal-emozionala eta instituzioarekiko lotura. Doikuntza akademikoak hainbat beharren aurrean ikasleak zer-nola egokitzen diren neurtzen du: lanak, azterketak eta ordutegiak; doikuntza sozialak, berriz, eskolan pertsonen arteko harremanak ebaluatzen 
ditu; doikuntza pertsonal-emozionalak, bestalde, eskolako ongizate fisiko eta psikologikoa aztertzen du; eta azkenik, azpieskala orokorrak ikasleek instituzioarekiko duten harremanaren kalitatea ikertzen du. Galdeketa horri esker, gerta litezkeen arazoak eta eskola-uzteak aldez aurretik hauteman daitezke, eta gerora esku hartu.

- Eskola Doikuntzaren Eskala Laburra (EBAE-10) eskola-doikuntza ebaluatzeko erabiltzen da (Moral de la Rubia et al., 2010). Tresna honek 10 item ditu, hiru dimentsiotan gauzatzen direnak: eskolaerrendimendua, itxaropen akademikoak eta eskolan integratzeko arazoak; era berean, eskola-doikuntzaren puntuazio orokor bat lortzen da, baita proposatzen dituen 3 azpieskaletan ere. Egileek diote beharrezkoa dela eskola-doikuntza neurtzea, batik bat, errendimendu akademikoa. Horretarako, auto-txostenak egiteaz gainera, espediente akademikoak eta ikasleen kalifikazioak ere hartu behar dira kontuan. Horiek horrela, errendimendu akademikoa nola neurtu ikertu denean, ikasleen errendimendu akademikoari buruz irakasleek egindako kalifikazioak erabili dira, baita ikasleen beren autopertzepzioa ere. Batzuetan, aipatu bi neurriak hartu dira kontuan (Huang, 2011).

Arestian aipatutakoez gainera, badira irakaslea iturritzat jotzen duten eskalak ikasleen doikuntzari buruzko informazioa eta eskolarekiko zer-nolako harremanak dituzten biltzeko eta ebaluatzeko:

- Irakasleak Hautemandako Eskola Doikuntzaren Eskala (PROF-A) (Cava et al., 2015), 14 item eta lau dimentsio dituena: errendimendu akademikoa, eskolako integrazioa (ikaskideekiko harremana), ikasle-irakasle arteko harremana eta familiaren inplikazioa (ikaslearen eskola-segimenduan). Eskala hori Irakasleek Ikasleak Ebaluatzeko Eskalaren (EA-P) (Cava eta Musitu, 1999b) bertsio zabala da, eskola-doikuntza eta errendimendua item eta faktore gutxiagorekin ere neurtzen dituena.

Modu horretan, hainbat egilek garrantzia ematen diote ez soilik ikasleen pertzepzioa biltzeari, baita irakasleek emandako informazioari eta familiek helarazitako datuei ere, ikasleen benetako eskola-doikuntzaren ikuspegi orokorrago eta objektiboago bat lortzeko (Hernando, Oliva, eta Pertegal, 2013).

2. taulan, eskola-doikuntza neurtzeko tresnak laburtzen dira, dimentsioekin lotuta. 
2. taula

Eskola-doikuntza neurtzeko tresna eta dimentsioak

\begin{tabular}{ll}
\hline \multicolumn{1}{c}{ Neurtzeko tresnak } & \multicolumn{1}{c}{ Eskola-doikuntzaren dimentsioak } \\
\hline $\begin{array}{l}\text { Autoritate Instituzionalarekiko Jarrera- } \\
\text { ren Eskala (Reicher eta Emler, 1985) }\end{array}$ & $\begin{array}{l}\text { (4) Sistemarekiko loturarik eza } \\
\text { Arau eta autoritatearen ideia } \\
\text { Harremanak eskolan }\end{array}$ \\
$\begin{array}{ll}\text { Unibertsitateko Doikuntzaren Eskala } \\
\text { (SACQ) (Baker eta Siryk, 1984, 1989) }\end{array}$ & $\begin{array}{l}\text { (4) Doikuntza akademikoa, soziala } \\
\text { eta pertsonal-emozionala } \\
\text { Instituzioarekiko lotura }\end{array}$ \\
$\begin{array}{ll}\text { Eskola Doikuntzaren Eskala Laburra } \\
\text { (EBAE-10) }\end{array}$ & $\begin{array}{l}\text { (3) Errendimendua eskolan } \\
\text { Itxaropen akademikoak }\end{array}$ \\
$\begin{array}{ll}\text { Arazoak eskola-integrazioan } \\
\text { Irakasleek Hautemandako Eskola Doi- }\end{array}$ \\
$\begin{array}{l}\text { kuntzaren Eskala (PROF-A) (Cava et } \\
\text { al., 2015) }\end{array}$ & $\begin{array}{l}\text { integrazioa, irakasle-ikasle harremana } \\
\text { eta familiaren inplikazioa }\end{array}$ \\
\hline
\end{tabular}

\section{ESKOLA-DOIKUNTZAREN ALDAKORTASUNA}

Atal honetan, sexuaren eta adinaren arabera egin diren eskola-doikuntzaren aldakortasunari buruzko ikerketak azalduko dira.

\subsection{Desberdintasunak sexuaren arabera}

Neskak eskolan doituago daudela erakusten duten ebidentziak izan badira: errendimendua, integrazioa, kide eta irakasleekiko harremana eta itxaropen akademikoak (Antonio-Agirre et al., 2015; Cerezo eta Ato, 2010; Droguett, 2011; Heras eta Navarro, 2012).

Errendimendu akademikoari dagokionez, eskola-doikuntzaren adierazlea izaki, ikerketa ugaritan egiaztatu da aipatu errendimendua handiago dela nesketan (Antonio-Agirre et al., 2015; Droguett, 2011; Fuentes, Alarcón, Gracia, eta García, 2015; Heras eta Navarro, 2012; Ibabe, 2016), motibazio handiagoa erakutsi eta ikasketetan denbora gehiago ematen dutelako (Hernando et al., 2013). Gainera, hainbat ikerketaren arabera, generoak errendimendu akademikoan du eragina; neskek errendimendu hobea dute ahozko ezagutzen arloetan (Costa eta Tabernero, 2012) eta mutilek, berriz, zientzietan eta matematiketan (González-Pienda et al., 2012; Suá- 
rez-Álvarez et al., 2014). Era berean, nerabeak aztergai diren beste ikerketa batek dio neskek errendimendu altuagoa dutela, 12-13 urte bitartean izan ezik, aldi horretan, mutilek izan ohi dituzte eta emaitza hobeak (Hernando, Oliva, eta Pertegal, 2012). Emaitzak biribilak ez badira ere, aipatutako egileen iritziz, zentroek generoa kontuan hartu behar dute, errendimenduan kalte egin dezaketen estereotipoak eta jarrerak saihesteko.

Beste ikerketa batzuek norberaren eraginkortasuna, generoa eta errendimendu akademikoaren arteko harremana aztertzen dute (Boz, YerdelenDamar, Aydemir, eta Aydemir, 2016). Neskek puntuazio askoz altuagoak lortu ohi dituzte, bai norberaren eraginkortasunean bai errendimenduan; norberaren eraginkortasunak eta generoak lotura estua erakusten dute, bada, errendimenduarekin.

Itxaropen akademikoei dagokienez, literatura zientifikoan desberdintasun nabarmenak frogatzen dira emakumeen alde nerabezaroan (AntonioAgirre et al., 2015; Droguett, 2011; Espinoza, Gillen-O’Neel, Gonzales, eta Fuligni, 2014; Heras eta Navarro, 2012; Suárez-Álvarez et al., 2014). Hain zuzen ere, badira ikerketa batzuk non irakasleek nesken itxaropen akademikoak positiboago azaltzen baitituzte (Cava eta Musitu, 1999a).

Integrazioaren ildotik, beste behin ere neska nerabeek puntuazio altuagoak lortzen dituzte eta mutilek, berriz, eskolan integratzeko arazo gehiago (Antonio-Agirre et al., 2015; Droguett, 2011; Heras eta Navarro, 2012), jokaera disruptibo gehiago (Fuentes et al., 2015), biktimizazio eta jokabidearazo gehiago erakusten dituzte (Liu, Lan, Hsu, Huang, eta Chen, 2014). Gainera, mutilek indarkeria handiagoa erabiltzen dutela erakutsi da (Povedano, Estévez, Martínez, eta Monreal, 2012; Shao, Liang, Yuan, eta Bian, 2014), baita eraso zuzena, ahozkoa eta fisikoa ere (Heras eta Navarro, 2012); gainerako kideek sarriago baztertzen dituztela ere frogatu da (Cava eta Musitu, 1999a).

\subsection{Desberdintasunak adinaren arabera}

Ikasle nerabeak eta gazteak bigarren hezkuntzan eta unibertsitatean daudenak dira. Zehatz-mehatz, nerabezaroa hiru etapatan bereizten da: lehenengo etapa (12-14 urte bitartean), erdiko etapa (15-17 urte bitartean) eta azken etapa (18-20); gaztaroan edo heldutasun goiztiarrean, berriz, 21-40 urte bitarteko adin-tartea barne hartzen da (Feldman, 2007). Nerabezaroa etapa erabakigarria da, doikuntza arriskuan jar dezaketen hainbat aldaketa jazo bailitezke hainbat mailatan. Gaztaroan, aldaketekin eta garapenarekin jarraitzen da.

Egile batzuek diote eskola-doikuntza areagotu egiten dela ikasleen heldutasunarekin edo adinak gora egiten duen heinean (Moral de la Rubia et al., 2010). Aldiz, beste ikertzaile batzuen ustez, eskola-doikuntza ona iragartzen da nerabezaroaren hasieran, baina beherakada bat, ordea, ne- 
rabezaroko erdiko etapan (15-17 urte bitartean) (Hernando et al., 2013); datu horiek nerabezaroa desdoikuntza-aldi kaltebera dela egiazta dezakete (Steinberg, 2005).

Errendimendu akademikoa, berriz, jaitsi egiten da nerabe-adinera iristean, nesken zein mutilen artean (Antonio-Agirre et al., 2015; Fuentes et al., 2015; Ibabe, 2016), baina are nabarmenagoa da mutilengan (Hernando et al., 2012, 2013). Errendimenduaren beherakada hainbat arrazoiri zor zaie: motibazioa gutxitzeari, ikasketei denbora gutxiago emateari eta loordu gutxiago izateari, jarduera fisikoetan eta eskolaz kanpokoetan parte hartzeari eta substantzien kontsumoa areagotzeari (Hernando et al., 2013).

Hala ere, ikerketa batzuei jarraiki, itxaropen akademikoetan ez da adinaren araberako desberdintasun nabaririk sumatzen (Antonio-Agirre et al., 2015). Beste batzuek, ordea, nerabezaroan itxaropen akademikoak jaitsi egiten direla frogatzen dute (Wang eta Eccles, 2011).

Ikasleen integrazioari dagokionez ere, emaitza desberdinak aurkitzen dira: ikerketa batean adinaren araberako desberdintasunak nabariak ez badira ere (Antonio-Agirre et al., 2015), beste lan batean, goi-mailako ikasketa akademikoetako ikasle nerabeek jokabide disruptibo gehiago dutela adierazten da (Fuentes et al., 2015) eta integrazio gutxiago behe-mailako ikasketen aldean, non eskolako giro hobea dagoela adierazten baitute. Baliteke goi-mailako ikasketetan hezkuntza-eskaera handiagoa izatea (eduki akademikoek garrantzi handiago dute) desberdintasun horien arrazoi. Bestalde, behe-mailako ikasketetan ikasleek interakzio gehiago dutela adierazi da (Cava eta Musitu, 1999a).

\section{ESKOLA-DOIKUNTZARI LOTUTAKO TESTUINGURU- ALDAGAIAK}

Azken urteetako ikerketa zientifikoei esker, eskola-doikuntzarekin lotutako hainbat testuinguru-aldagai identifikatu dira. Gurasoek jokabide positiboak badituzte - parte-hartzea eta laguntza - , gazteek doikuntza akademikoko maila altua lortuko dutela aurreikusten da (Ratelle, Duchesne, eta Guay, 2017), batik bat neskek. Gauzak horrela, eskola-doikuntzaren eta laguntza sozialaren arteko lotura positiboa da unibertsitateko ikasleengan (Chui eta Chan, 2017). Era berean, ikasle nerabeei dagokienez, familia-estilo bihozbera izateak, alegia, laguntza, parte-hartzea, elkarrizketa eta afektua oinarri dituen familia bat izateak, lotura du eskola-doikuntza handiagoa izatearekin, errendimendu akademiko eta autokontzeptu akademiko hobearekin eta jokabide disruptibo gutxiago izatearekin (Fuentes et al., 2015). Gainera, ikasle-irakasleen arteko harremanen kalitatea eta hurbiltasuna oso garrantzitsuak dira eskola-desdoikuntza saihesteko, bereziki hezkuntza-etapen trantsizioetan jazo ohi diren aldaketei aurre egiteko; interakzioan hurbiltasuna agertzen bada, errendimendua altuagoa izango da (Longobardi, 
Prino, Marengo, eta Settanni, 2016). Errendimendu akademikoan eragin positiboa dute, era berean, eskola-asistentziak eta jokaera egokituak (Feldman et al., 2014). Era berean, kideekiko harreman positiboek zerikusia dute eskola-doikuntzarekin (Wentzel, Russell, eta Baker, 2014).

Bestalde, jazotzen den diskriminazioak ondorio negatiboak ekar ditzake nerabearen eskola-doikuntzan eta errendimendu akademikoan (Hood, Bradley, eta Ferguson, 2017). Ikerketa batzuen arabera, kideen arteko biktimizazioak errendimendu akademiko negatiboarekin lotura estua izateaz gainera, eskola-absentismoarekin ere badu zerikusia (Wormington, Anderson, Schneider, Tomlinson, eta Brown, 2016) baita jokaera arazoekin ere (Feldman et al., 2014); gainera, azpimarratzen da biktimizazioak eta jokaera-arazoek eskolako giro negatiboa hautemanarazten dutela, lagunak egiteko jarrera pasiboagoa erakusten dutela eta ikasketekin jarraitzeko itxaropen gutxi izaten dela (Liu et al., 2014).

Azkenik, ikasleen itxaropen akademikoek lotura estua dute gurasoen laguntzarekin eta helburu akademikoekin, baita jokabide-arazo gutxiago izatearekin ere (Gerard eta Booth, 2015). Ikasleek nerabezaroan dituzten hezkuntza-itxaropenak eta gurasoen laguntza, baita lagunena ere, lotesle direla azaltzen du ikerketa batek (Espinoza et al., 2014).

\section{ONDORIOAK}

Eskola-doikuntza egokitzapen positiboaren adierazlea dela frogatu da, bai nerabezaroan, bai gaztaroan, eta zeregin ebolutiboei behar bezala aurre egiten laguntzen dien gaitasun sozialarekin lotzen da (Rodríguez-Fernández et al., 2016). Aldagai hau interesgarria da ez soilik nerabezaroan eta gaztaroan dauden aldi ebolutiboetan jazotzen den egokitzapen sozialarekin lotzen delako, baizik eta esku hartzeko aukera bat delako lorpen akademikoa, itxaropen akademiko altuak eta kide eta irakasleekiko jokabide egokia izate aldera. Era berean, aipatu aldagaia sustatuz gero, eskolan behar bezala egokitu ahal izatea eragozten duten hainbat faktore ekidin daitezke, hala nola, eskola-porrota, itxaropen negatiboak, integrazio-arazoak eta indarkeria eskolaren inguruan (Estévez et al., 2007).

Duela gutxi, ikerkuntzan eskola-doikuntzaren kontzeptualizazioari buruzko eta hori zehaztasun enpirikoz neurtzeko aldagaiei buruzko eztabaida sortu da (Cava et al., 2015). Ondorioz, gaur egun eskola-doikuntza interes handia piztu duen konstruktutzat identifikatu da hezkuntza-alorrean, ikasle nerabeen garapen sozial onena lortzeko elementu garrantzitsua delako. Bestalde, sexuaren eta adinaren araberako eskola-doikuntzaren aldakortasunari buruzko emaitza enpirikoak biribilak ez diren arren, emaitzak nesken eta nerabe gazteenen aldekoak izan ohi dira oro har. Halaber, azpimarratzen da garrantzitsua dela, batetik, generoa kontuan hartzea zentroetan errendimendu akademikoari kalte egin diezaioketen estereotipoak lantzeko 
(González-Pienda et al., 2012), eta bestetik, nerabezaroko etapa ikasleen doikuntza-aldi funtsezkotzat jotzea (Feldman, 2007). Ikuspegi ekologikotik, eskola-doikuntza bestelako hezkuntza- eta testuinguru-aldagaiekin aztertu da, hau da, irakasleen eta familiaren jokabide positiboen (Longobardi et al., 2016), familia-estilo bihozberaren (Fuentes et al., 2015) eta kideekiko harreman positiboen ondorio gisa (Wentzel et al., 2014). Edonola ere, ikaslearen ingurunea oso garrantzitsua da, horregatik ikertzaileak hainbat aldagaik eskola-doikuntzan duten eragina ikertzen ari dira.

Labur esanda, eskola-doikuntza hezkuntzaren arloan ikerketa-ildo ireki aberatsa da, nerabezaroan eta gaztaroan egokitzapen sozialaren adierazlea izaki. Era berean, irakaskuntza-komunitateak, hots, ikaslearen inguruko hezkuntza-agente guztiek, gehiago inplikatu beharko lukete. Gaur egun, eskola-doikuntzak ikergai garrantzitsua izaten jarraitzen du, eta orain arte lortu diren emaitzen arabera, hezkuntza-programak egin eta ezarri behar dira eskolan, familian eta komunitatean, ikasle nerabe eta gazteen garapen onena sustatu eta desegokitasun sozialari aurrea hartzeko.

\begin{abstract}
School adjustment is a significant factor for positive development in adolescence and youth. In this study, an updated theoretical revision on the previous research is conducted about school adjustment's concept, indicators, explanatory models and measures. Besides, variability in school adjustment is an alysed according to sex and age as well as its relationship with contextual variables of students. Despite a lack of agreement regarding the conceptualization of the construct, a multifactorial structure is currently accepted. The indicators analysed include: academic performance, expectations and social integration. Although differences between sex and age are not decisive, results, in general, tend to be favourable to girls and early adolescence. Likewise, the influence of contextual variables onschool adjustment is confirmed, such as perceived support from teachers, family and peers. Finally, conclusions are developed.
\end{abstract}

Keywords: school adjustment, academic performance, school integration, academic expectations, adolescence, revision. 
El ajuste escolar es un relevante indicador de desarrollo positivo en la adolescencia y juventud. En este trabajo se realiza una revisión teórica actualizada de las principales contribuciones que la investigación previa ofrece sobre elconcepto, los indicadores, los modelos explicativos y la medida del ajuste escolar. Además, se analiza la variabilidad del ajuste escolar en función del sexo y la edad, así como su relación con variables contextuales del alumnado. Si bien no existe acuerdo en la conceptualización del constructo, actualmente se constata la estructura multifactorial del ajuste escolar. Entre sus indicadores se encuentran: el rendimiento escolar, las expectativas académicas y la integración escolar. Aunque las diferencias de sexo y edad tampoco son concluyentes, los resultados, en general, tienden a favorecer a las chicas y a la adolescencia temprana. Asimismo, se corrobora la influencia de las variables contextuales sobre el ajuste escolar, como el apoyo percibido del profesorado, la familia y los iguales. En último lugar, se desarrollan las conclusiones.

Palabras clave: ajuste escolar, rendimiento académico, integración escolar, expectativas académicas, adolescencia, revisión.

L'ajustement scolaire est un indicateur significatif de développement positif chez les adolescents et les jeunes. Dans ce travail, on effectue une révision théorique actualisée des principales contributions que la recherche précédente offre sur le concept, les indicateurs, les modèles explicatifs et la mesure de l'ajustement scolaire. En outre, on analyse la variabilité de l'ajustement scolaire selon le sexe et l'âge comme leur rapport avec les variables contextuelles des élèves. Bien qu'il n'y ait pas un accord sur laconceptualisation de la construction, on constate actuellement la structure multifactorielle de l'ajustement scolaire. Parmi les indicateurs se trouvent la performance scolaire, les attentes académiques et l'intégration scolaire. Même si les différences de sexe et d'âge ne sont pas concluantes, les résultats, en général, tendent à favoriser les filles et le début de l'adolescence. De même, on corrobore l'influence des variables contextuelles de l'ajustement scolaire comme le soutien perçu du côté des professeurs, de la famille et des pairs. En dernier lieu, les conclusions sont développées.

Mots-clé: ajustement scolaire, performance scolaire, intégration scolaire, attentes académiques, adolescence, révision. 


\section{ERREFERENTZIAK}

Adell, M. A. (2006). Estrategias para mejorar el rendimiento académico de los adolescentes. Madril: Pirámide.

Álvarez-García, D., Núñez, J. C., Rodríguez, C., Álvarez, L., eta Dobarro, A. (2011). Propiedades psicométricas del Cuestionario de Violencia Escolar Revisado (CUVE-R). Revista de Psicodidáctica, 16(1), 59-83.

Antonio-Agirre, I., Azpiazu, L., Esnaola, I., eta Sarasa, M. (2015). Predictive ability of self-concept and emotional intelligence in perceived school adjustment. Bordon-Revista de Pedagogia, 67(4), 9-25. doi:10.13042/Bordon.2015.67401

Azpiazu, L., Esnaola, I., eta Ros, I. (2014). Factores contextuales y variables individuales en el ajuste escolar. International Journal of Developmental and Educational Psychology Revista INFAD de Psicología, 6(1), 327-336. doi:10.17060/ijodaep.2014.n1.v6.751

Baker, R. W., eta Siryk, B. (1984). Measuring adjustment to college. Journal of Counseling Psychology, 31(2), 179-189. doi:10.1037/0022-0167.31.2.179

Baker, R. W., eta Siryk, B. (1989). Manual of the SACQ. Los Ángeles: Western Psychological Services.

Bandura, A. (1997). Self-efficacy: The exercise of control. New York: Freeman.

Bandura, A. (2001). Social cognitive theory: An agentic perspective. Annual Review of Psychology, 52(1), 1-26. doi:10.1146/annurev.psych.52.1.1

Bandura, A., Barbaranelli, C., Caprara, G. V., eta Pastorelli, C. (2001). Self- efficacy beliefs as shapers of children's aspirations and career trajectories. Child Development, 72(1), 187-206. doi:10.1111/1467-8624.00273

Boz, Y., Yerdelen-Damar, S., Aydemir, N., eta Aydemir, M. (2016). Investigating the relationships among students' self-efficacy beliefs, their perceptions of classroom learning environment, gender, and chemistry achievement through structural equation modeling. Research in Science \& Technological Education, 34(3), 307-324. doi:10.1080/02635143.2016.1174931

Bronfenbrenner, U. (1979). The ecology of human development: Experiments by nature and design. Cambridge: Harvard University Press.

Cava, M. J., eta Musitu, G. (1999a). La integración escolar: un análisis en función del sexo y el curso académico de los alumnos. Revista española de Orientación y Psicopedagogía, 10(18), 297-314.

Cava, M. J., eta Musitu, G. (1999b). Percepción del profesor y estatus sociométrico en el grupo de iguales. Información Psicológica, 71, 60-65.

Cava, M. J., Povedano, A., Buelga, S., eta Musitu, G. (2015). Análisis psicométrico de la Escala de Ajuste Escolar Percibido por el Profesor (PROF-A). Psychosocial Intervention, 24(2), 63-69. doi:10.1016/j.psi.2015.04.001

Cerezo, F., eta Ato, M. (2010). Estatus social, género, clima del aula y bullying entre estudiantes adolescentes. Anales de Psicología, 26(1), 137-144.

Chui, R. C. F., eta Chan, C. K. (2017). School Adjustment, Social Support, and Mental Health of Mainland Chinese College Students in Hong Kong. Journal of College Student Development, 58(1), 88-100. doi:10.1353/csd.2017.0005

Costa, S., eta Tabernero, C. (2012). Rendimiento académico y autoconcepto en estudiantes de educación secundaria obligatoria según el género. Revista Iberoamericana de Psicología y Salud, 3(2), 175-193. 
Damon, W. (2004). What is positive youth development? Annals of the American Academy of Political and Social Science, 591, 13-24. doi:10.1177/0002716203260092

Droguett, L. (2011). Rasgos psicológicos asociados al ajuste social y personal de alumnado adolescente (Doktoretza-tesia). Euskal Herriko Unibertsitatea, Leioa.

Eccles, J. S., eta Wigfield, A. (2002). Motivational beliefs, values, and goals. Annual Review of Psychology, 53(1), 109-132. doi:10.1146/annurev. psych.53.100901.135153

Espinoza, G., Gillen-O’Neel, C., Gonzales, N. A., eta Fuligni, A. J. (2014). Friend affiliations and school adjustment among Mexican-American adolescents: The moderating role of peer and parent support. Journal of Youth and Adolescence, 43(12), 1969-1981. doi:10.1007/s10964-013-0023-5

Estévez, E., Murgui, S., Ruiz, Moreno, D., eta Musitu, G. (2007). Estilos de comunicación familiar, actitud hacia la autoridad institucional y conducta violenta del adolescente en la escuela. Psicothema, 19(1), 108-113.

Feldman, R. S. (2007). Desarrollo psicológico a través de la vida. Mexiko: Pearson Educación.

Feldman, M. A., Ojanen, T., Gesten, E. L., Smith- Schrandt, H., Brannick, M., Totura, C. M. W., ... eta Brown, K. (2014). The effects of middle school bullying and victimization on adjustment through high school: Growth modeling of achievement, school attendance, and disciplinary trajectories. Psychology in the Schools, 51(10), 1046-1062. doi:10.1002/pits.21799

Froiland, J. M., eta Davison, M. L. (2016). The longitudinal influences of peers, parents, motivation, and mathematics course-taking on high school math achievement. Learning and Individual Differences, 50, 252-259. doi:10.1016/j. lindif.2016.07.012

Fuentes, M. C., Alarcón, A., Gracia, E., eta García, F. (2015). El ajuste escolar en los adolescentes españoles: influencia de la socialización parental. Cultura y Educación, 27(1), 1-32. doi:10.1080/11356405.2015.1006847

Gerard, J. M., eta Booth, M. Z. (2015). Family and school influences on adolescents' adjustment: The moderating role of youth hopefulness and aspirations for the future. Journal of Adolescence, 44, 1-16. doi:10.1016/j. adolescence.2015.06.003

González-Pienda, J. A., Fernández-Cueli, M., García, T., Suárez, N., Fernández, E., Tuero-Herrero, E., eta da Silva, E. H. (2012). Diferencias de género en actitudes hacia las mataméticas en la enseñanza obligatoria. Revista Iberoamericana de Psicología y Salud, 3(1), 55-73.

Hargreaves, D. (1978). Las relaciones interpersonales en la educación. Madril: Narcea.

Harrison, L. J., Clarke, L., eta Ungerer, J. A. (2007). Children's drawings provide a new perspective on teacher-child relationship quality and school adjustment. Early Childhood Research Quarterly, 22(1), 55-71. doi:10.1016/j. ecresq.2006.10.003

Heras, J., eta Navarro, R. (2012). Ajuste escolar, soledad y conducta agresiva entre estudiantes de Educación Secundaria. Qurriculum: Revista de Teoría, Investigación y Práctica Educativa, 25, 105-124. 
Hernando, Á., Oliva, A., eta Pertegal, M. Á. (2012). Variables familiares y rendimiento académico en la adolescencia. Estudios de Psicología, 33(1), 51-65. doi:10.1174/021093912799803791

Hernando, Á., Oliva, A., eta Pertegal, M. Á. (2013). Diferencias de género en los estilos de vida de los adolescentes. Psychosocial Intervention, 22(1), 15-23. doi:10.5093/in2013a3

Hood, W., Bradley, G. L., eta Ferguson, S. (2017). Mediated effects of perceived discrimination on adolescent academic achievement: A test of four models. Journal of Adolescence, 54, 82-93. doi:10.1016/j.adolescence.2016.11.011

Huang, C. (2011). Self-concept and academic achievement: A meta-analysis of longitudinal relations. Journal of School Psychology, 49(5), 505-528. doi:10.1016/j.jsp.2011.07.001

Ibabe, I. (2016). Academic failure and child-to-parent violence: family protective factors. Frontiers in Psychology, 7, 1-11. doi:10.3389/fpsyg.2016.01538

Kiefer, S. M., eta Ryan, A. M. (2008). Striving for social dominance over peers: The implications for academic adjustment during early adolescence. Journal of Educational Psychology, 100(2), 417-428. doi:10.1037/0022-0663.100.2.417

Kiuru, N., Aunola, K., Nurmi, J. E., Leskinen, E., eta Salmela-Aro, K. (2008). Peer group influence and selection in adolescents' school burnout: A longitudinal study. Merrill-Palmer Quarterly, 54(1), 23-55.

Kiuru, N., Aunola, K., Vuori, J., eta Nurmi, J. E. (2007). The role of peer groups in adolescents' educational expectations and school adjustment. Journal of Youth and Adolescence, 36(8), 995-1009. doi:10.1007/s10964-006-9118-6

Kiuru, N., Nurmi, J. E., Aunola, K., eta Salmela-Aro, K. (2009). Peer group homogeneity in adolescents' school adjustment varies according to peer group type and gender. International Journal of Behavioral Development, 33(1), 65-76. doi: $10.1177 / 0165025408098014$

Ladd, G. W . (1989). Children's social competence and social supports: Precursors of early school adjustment? B. Schneider, G. Attili, J. Nadel eta R. Weissberg-en (Edk.), Social competence in developmental perspective (orr. 277 291). Holanda: Kluwer. doi:10.1007/978-94-009-2442-0

Ladd, G. W., Kochenderfer- Ladd, B., eta Rydell, A. M. (2011). Children's Interpersonal Skills and School-Based Relationships. P. K. Smith eta C. H. Hart-en (Edk.), The Wiley-Blackwell Handbook of Childhood Social Development (orr. 181-206). Oxford, UK: Wiley-Blackwell. doi:10.1002/9781444390933.ch10

Lee, J., eta Shute, V. J. (2010). Personal and social-contextual factors in K-12 academic performance: An integrative perspective on student learning. Educational Psychologist, 45(3), 185-202. doi:10.1080/00461520.2010.493471

Lent, R. W., Brown, S. D., eta Hackett, G. (1994). Toward a unifying social cognitive theory of career and academic interest, choice, and performance. Journal of Vocational Behavior, 45(1), 79-122. doi:10.1006/jvbe.1994.1027

Lippman, L. H., Anderson-Moore, K., Guzman, L., Ryberg, R., McIntosh, H., Ramos, M. F., ... eta Kuhfeld, M. (2014). Flourishing children: Defining and testing indicators of positive development. Nueva York: Springer. doi: 10.1007/978-94- 017-8607-2

Liu, M. C. C., Lan, C. C., Hsu, J. W., Huang, K. L., eta Chen, Y. S. (2014). Bullying victimization and conduct problems among high school students in Taiwan: Focus on fluid intelligence, mood symptoms and associated psychosocial 
adjustment. Children and Youth Services Review, 47, 231-238. doi:10.1016/j. childyouth.2014.09.011

Longobardi, C., Prino, L. E., Marengo, D., eta Settanni, M. (2016). Studentteacher relationships as a protective factor for school adjustment during the transition from middle to high school. Frontiers in Psychology, 7(1988), 1-9. doi:10.3389/fpsyg. 2016.01988

Madariaga, J. M., Arribillaga, A., eta Zulaika, L. M. (2014). Componentes y relaciones de un modelo estructural del ajuste psicosocial en la adolescencia. Internacional Journal of Developmental and Educational Psychology (INFAD), 6(1), 303-310. doi:10.17060/ijodaep.2014.n1.v6.748

Martínez-Ferrer, B. (2009). Ajuste escolar, rechazo y violencia en adolescentes (Doktoretza-tesia). Valentziako Unibertsitatea, Valentzia.

McAbee, S. T., Oswald, F. L., eta Connelly, B. S. (2014). Bifactor model of personality and college student performance: A broad versus narrow view. European Journal of Personality, 28(6), 604-619. doi:10.1002/per.1975

Moral de la Rubia, J. C., Sánchez-Sosa, J. C., eta Villarreal-González, M. E. (2010). Desarrollo de una escala multidimensional breve de ajuste escolar. REMA Revista Electrónica de Metodología Aplicada, 15(1), 1-11.

Núñez, J. C., Vallejo, G., Rosário, P., Tuero, E., eta Valle, A. (2014). Variables del estudiante, del profesor y del contexto en la predicción del rendimiento académico: análisis desde una perspectiva multinivel. Revista de Psicodidáctica, 19(1), 145-172. doi:10.1387/RevPsicodidact.7127

Nurmi, J. E. (2004). Socialization and self-development: Channeling, selection, adjustment, and reflection. R. M. Lerner eta L. Steinberg-en (Edk.), Handbook of adolescent psychology (2. ed., orr. 85-124). Hoboken, NJ: John Wiley \& Sons.

Oliva, A., Ríos, M., Antolín, L., Parra, A., Hernando, A., eta Pertegal, M. A. (2010). Más allá del déficit: Construyendo un modelo de desarrollo positivo adolescente. Infancia y Aprendizaje, 33(2), 223-234. doi:10.1174/021037010791114562

Povedano, A., Estévez, E., Martínez, B., eta Monreal, M. C. (2012). Un perfil psicosocial de adolescentes agresores y víctimas en la escuela: análisis de las diferencias de género. Revista de Psicología Social, 27(2), 169-182. doi:10.1174/021347412800337906

Ratelle, C. F., Duchesne, S., eta Guay, F. (2017). Predicting school adjustment from multiple perspectives on parental behaviors. Journal of Adolescence, 54, 60-72. doi:10.1016/j.adolescence.2016.11.008

Reicher, S. eta Emler, N. (1985). Delinquent behavior and attitudes to formal authority. British Journal of Social Psychology, 3, 161-168. doi:10.1111/j.20448309.1985.tb00677

Rodríguez-Fernández, A., Droguett, L., eta Revuelta, L. (2012). Ajuste escolar y personal en la adolescencia: el papel del autoconcepto académico y del apoyo social percibido. Revista de Psicodidáctica, 17(2), 397-415. doi:10.1387/Rev. Psicodidact.3002

Rodríguez-Fernández, A., Ramos-Díaz, E., Madariaga, J. M., Arrivillaga, A., eta Galende, N. (2016). Steps in the construction and verification of an explanatory model of psychosocial adjustment. European Journal of Education and Psychology, 9(1), 20-28. doi:10.1016/j.ejeps.2015.11.002 
Rosário, P., Lourenço, A., Paiva, O., Rodrigues, A., Valle, A., eta Tuero-Herrero, E. (2012). Predicción del rendimiento en matemáticas: efecto de variables personales, socioeducativas y del contexto escolar. Psicothema, 24(2), 289-295.

Rosário, P., Núñez, J. C., Valle, A., Paiva, O., eta Polydoro, S. (2013). Enfoques de enseñanza en Bachillerato en función de variables contextuales y del docente. Revista de Psicodidáctica, 18(1), 25-45. doi:10.1387/RevPsicodidact.6215

Seligman, M., eta Csikszentmihalyi, M. (2000). Positive Psychology: An Introduction. American Psychologist, 55, 5-14. doi:10.1037//0003-066X.55.1.5

Shao, A., Liang, L., Yuan, C., eta Bian, Y. (2014). A latent class analysis of bullies, victims and aggressive victims in chinese adolescence: relations with social and school adjustments. Plos One, 9(4), 1-8. doi:10.1371/journal. pone. 0095290

Steinberg, L. (2005). Cognitive and affective development in adolescence. Trends in Cognitive Sciences, 9(2), 69-74. doi:10.1016/j.tics.2004.12.005

Suárez-Álvarez, J., Fernández-Alonso, R., eta Muñiz, J. (2014). Self-concept, motivation, expectations, and socioeconomic level as predictors of academic performance in mathematics. Learning and Individual Differences, 30, 118-123. doi:10.1016/j.lindif.2013.10.019

Torres, L. E., eta Rodríguez, N. Y. (2006). Rendimiento académico y contexto familiar en estudiantes universitarios. Enseñanza e Investigación en Psicología, 11(2), 255-270.

Valle, A., Regueiro, B., Rodríguez, S., Piñeiro, I., Freire, C., Ferradás, M., eta Suárez, N. (2015). Perfiles motivacionales como combinación de expectativas de autoeficacia y metas académicas en estudiantes universitarios. European Journal of Education and Psychology, 8(1), 1-8. doi:10.1016/j.ejeps.2015.10.001

Wang, M. T., eta Eccles, J. S. (2011). Adolescent behavioral, emotional, and cognitive engagement trajectories in school and their differential relations to educational success. Journal of Research on Adolescence, 22(1), 31-39. doi: $10.1111 / \mathrm{j} .1532-7795.2011 .00753$

Wentzel, K., Russell, S., eta Baker, S. (2014). Peer relationships and positive adjustment at school. M. J. Furlong, R. Gilman eta E. S. Huebner-en (Edk.), Handbook of positive psychology in schools (2. ed., orr. 229-243). Oxford, Ingalaterra: Routledge.

Wormington, S. V., Anderson, K. G., Schneider, A., Tomlinson, K. L., eta Brown, S. A. (2016). Peer victimization and adolescent adjustment: does school belonging matter? Journal of School Violence, 15(1), 1-21. doi:10.1080/153882 20.2014.922472

Zalazar-Jaime, M. F., Cupani, M., eta De Mier, M. V. (2015). Evaluation of the performance model of Social Cognitive Theory of Career: contributions of differential learning experiences. Bordón, 67(4), 153-168. doi:10.13042/ Bordon.2015.67410

Zuffianò, A., Alessandri, G., Gerbino, M., Luengo, B. P., Di Giunta, L., Milioni, M., eta Caprara, G. V. (2013). Academic achievement: The unique contribution of self-efficacy beliefs in self-regulated learning beyond intelligence, personality traits, and self-esteem. Learning and Individual Differences, 23, 158162. doi:10.1016/j.lindif.2012.07.010 